\title{
Evidence That Glycine Mediates the Postsynaptic Potentials That Inhibit Lumbar Motoneurons During the Atonia of Active Sleep
}

\author{
Michael H. Chase, Peter J. Soja, and Francisco R. Morales \\ Departments of Physiology and Anatomy and the Brain Research Institute, UCLA School of Medicine, Los Angeles, \\ California 90024
}

Postsynaptic inhibition of somatic motoneurons underlies the atonia of active sleep. This inhibitory control depends, in large measure, on the bombardment of motoneurons during active sleep by a unique class of large-amplitude inhibitory postsynaptic potentials (IPSPs). These potentials are present only during this behavioral state and have therefore been designated as active sleep-specific IPSPs (AS-IPSPs). The present study was concerned with determining the neurotransmitter that mediates these AS-IPSPs.

Lumbar motoneurons were recorded intracellularly during quiet and active sleep in intact, undrugged, normally respiring cats. The frequency and waveform parameters of the inhibitory postsynaptic potentials recorded from these motoneurons were examined following the microiontophoretic juxtacellular administration of strychnine (a glycine receptor antagonist) and picrotoxin and bicuculline (GABA receptor antagonists).

Microiontophoretically applied strychnine abolished the ASIPSPs and a majority of smaller-amplitude IPSPS. Neither picrotoxin nor bicuculline modified the frequency, amplitude, or rising phase of the AS-IPSPs or the smaller-amplitude IPSPs. We conclude that the postsynaptic inhibitory drive that impinges on motoneurons during active sleep is principally mediated by glycine or a glycinergic substance.

During the state of active sleep, lumbar motoneurons receive a sustained barrage of inhibitory postsynaptic potentials (IPSPs; Morales et al., 1987). These IPSPs, which contribute to the suppression of motoneuron activity that occurs during this behavioral state, were divided into 2 groups. The first group consisted of IPSPs that were characterized by their large amplitude; these have been designated as "active sleep-specific" (AS-IPSPs) because they are only present during active sleep (Morales and Chase, 1982; Morales et al., 1987). The second group comprised IPSPs that were smaller in amplitude and resembled IPSPs that were present during quiet sleep and wakefulness as well as during active sleep (Morales and Chase, 1982; Morales et al., 1987).

The present study was performed to determine whether the inhibitory amino acids, glycine and GABA, mediate the IPSPs of active sleep. We focused our attention on glycine and GABA

Received Apr. 5, 1988; revised July 29, 1988; accepted Aug. 1, 1988.

This work was supported by grants from the U.S. Public Health Service (NS 23426 and MH 43362). We wish to thank Mr. W. Vota for developing the computer software employed in this study.

Correspondence should be addressed to Michael Chase, Department of Physiology, UCLA School of Medicine, Center for Health Sciences, Los Angeles, CA 90024-1746-18.

Copyright (C) 1989 Society for Neuroscience $0270-6474 / 89 / 030743-09 \$ 02.00 / 0$ because these substances have been implicated in the postsynaptic inhibition of spinal cord motoneurons in anesthetized and in acutely prepared decerebrate animals (see reviews by Curtis, 1969; Davidoff and Hackman, 1983; Young and MacDonald, 1983).

Our experimental approach was to examine the effect of antagonists of glycine (i.e., strychnine) and GABA (i.e., picrotoxin and bicuculline) on the frequency of occurrence and on the waveform parameters of the IPSPs that occur during the non-REM periods of active sleep. The convulsant properties of strychnine, picrotoxin, and bicuculline and their effects on numerous physiological systems and cell groups (Curtis, 1969) precluded their systemic or intrathecal injection. Therefore, to circumvent these problems and to localize the site of action of these inhibitory neurotransmitter antagonists, they were administered juxtacellularly, by microiontophoresis, onto the surface of motoneurons that were being recorded intracellularly during naturally occurring episodes of quiet and active sleep. Portions of this work have been presented previously (Morales et al., 1984; Soja et al., 1986).

\section{Materials and Methods}

Chronic implant procedures. Experiments were performed on 5 intact unanesthetized, normally respiring cats. Complete details regarding the surgical procedures for preparing the lumbar vertebral column for intracellular recording of motoneurons in the chronic cal have been presented in previous publications, as have procedures for recording pontogeniculo-occipital (PGO) waves, the cortical EEG, and the states of sleep and wakefulness (Morales et al., 1981).

Intracellular recording and microiontophoretic procedures. The sciatic motoneuron pools were located using a single-barrel glass micropipette filled with $2 \mathrm{M} \mathrm{K}^{+}$-citrate. After locating these pools, the single-barrel micropipette was removed and replaced with an electrode that was composed of parallel glass micropipettes (Soja et al., 1987). One micropipette was used for intracellular recording; 2 other micropipette barrels were used for the microiontophoretic ejection of substances. The tips of the recording and drug barrels were staggered [mean intertip distance, $70.0 \pm 11.5 \mu \mathrm{m}$ (SD)] so that substances could be released next to the motoneuron soma from which intracellular records were obtained. A mixture of dental cement and quick-drying cyanoacrylate was used to bond the barrels and shanks of the pipettes together; the composite micropipette assembly was then coated with a thin film of water-insoluble dental sealant. Details regarding the configuration of the micropipette tips were noted for each electrode and compared with measurements taken immediately after recording periods. Data obtained with composite electrodes whose tip configurations differed markedly after a recording session from their original dimensions were discarded.

The intracellular recording micropipette, which was filled with $2 \mathrm{M}$ $\mathrm{K}^{+}$-citrate, was utilized to monitor the activity of sciatic motoneurons, which were identified by antidromic nerve stimulation via a permanently implanted peripheral nerve cuff electrode (Morales et al., 1981). One of the ejection micropipettes, depending on the drug to be tested, 


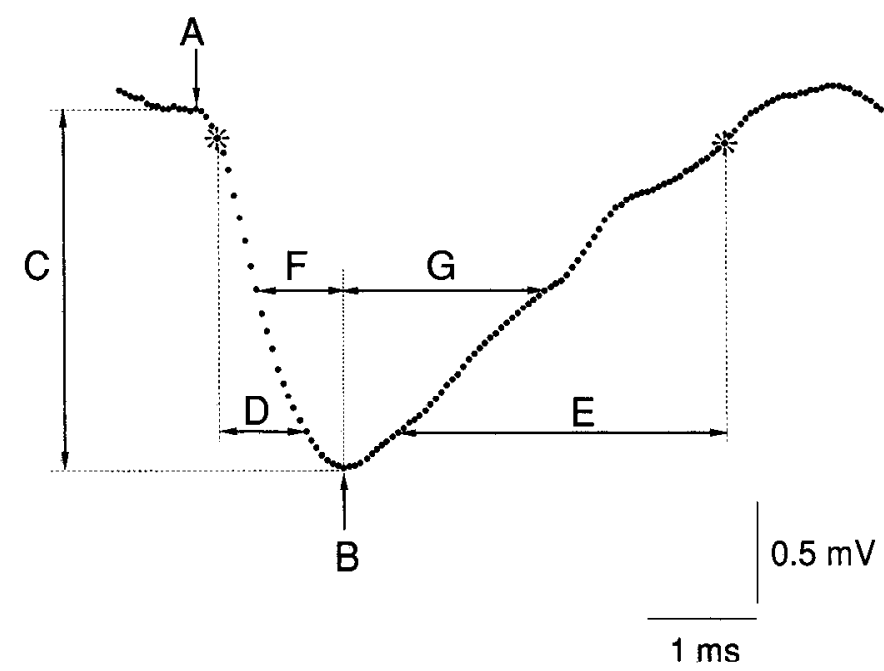

Figure 1. Example of a digitized ( $50 \mu \mathrm{sec} / \mathrm{bin})$ spontaneously occurring IPSP recorded from a lumbar motoneuron during the state of active sleep. A computerized system (Morales et al., 1985) was used to digitize the membrane potential, identify IPSPs, and calculate their frequency of occurrence and individual waveform parameters, as illustrated by letters $A-G$. $A$ and $B$, data points that define the foot and peak, respectively, of each IPSP; $C$, amplitude of the IPSP determined by the absolute voltage difference between $B$ and $A ; D, 10-90 \%$ rise time (the asterisk on the rising phase indicates the data point nearest to $10 \%$ of the potential's amplitude); $E, 10-90 \%$ decay time (the asterisk on the decay phase indicates the data point nearest to $90 \%$ of the potential's decay time); $F$ and $G$ together, IPSP half-width; $G$, IPSP half-decaywidth. The amplitude of this spontaneous IPSP was $1.76 \mathrm{mV}$; its $10-$ $90 \%$ rise time, $10-90 \%$ decay time, half-width, and half-decay-width were $0.75,2.95,2.70$, and $1.90 \mathrm{msec}$, respectively. Antidromic spike amplitude, $71 \mathrm{mV}$.

was filled with either of the following solutions, which was prepared fresh on the day of each experiment: strychnine nitrate $(10-15 \mathrm{~mm}$ in $165 \mathrm{~mm} \mathrm{NaCl}, \mathrm{pH} \mathrm{6.5),} \mathrm{picrotoxin} \mathrm{(saturated} \mathrm{solution} \mathrm{in} 165 \mathrm{~mm} \mathrm{NaCl}$, pH 6.5), or bicuculline methiodide (10 mM, in $165 \mathrm{~mm} \mathrm{NaCl}, \mathrm{pH} 4.0$ ). The remaining ejection micropipette was filled with a $\mathrm{NaCl}$ solution (165 mM), which was used for automatic current neutralization. Substances were released by applying a constant current to the ejection barrel (which was made relatively positive) from a programmable current generator (Medical Systems, Neurophore BH-2). "Backing" currents $(-10 \mathrm{nA})$ were routinely applied to the ejection barrels. The effect of each amino acid antagonist on lumbar motoneurons was examined scparatcly during any given recording scssion.

Membrane potential activity was recorded using a high-input-impedance amplifier. The membrane potential activity was monitored on an oscilloscope; it was also recorded on a polygraph and stored on magnetic media (FM tape recorder, Vetter Model D). In addition, the EEG, EMG, EOG, and PGO activity as well as a voltage signal denoting the onset and duration of drug ejection were recorded on tape.

Analysis of the frequency and waveform of spontaneous IPSPS. The frequency and waveform characteristics of IPSPs were analyzed using a microcomputer system which first digitized the tape-recorded membrane potential and then stored the data on hard disk cartridges (Morales et al., 1985). Inhibitory synaptic potentials were detected automatically and displayed on a graphics terminal; their frequency and waveform characteristics were then determined. Data segments of the high-gain intracellular recordings were sampled from each motoneuron during quiet sleep and the non-rapid eye movement periods of active sleep. ${ }^{1}$ IPSPs were classified as simple inhibitory potentials (i.e., those potentials that did not possess inflections on their rising phase), as well as composite inhibitory potentials (Morales et al., 1985). IPSP frequency was expressed as the number of potentials (single and composite) per second.

'The IPSPs that occur during the REM periods of AS were not analyzed in the present study because of the large fluctuations in membrane potential and motoneuron discharge present during these episodes (Chase and Morales, 1982, 1983).
For the determination of waveform parameters, only simple IPSPs were examined; special attention was paid to exclude from the waveform analysis not only those potentials whose decay (i.e., repolarization) phase was interrupted by other spontaneous potentials, but also potentials that did not return to within $10 \%$ of their initial zero voltage level (or foot, see Fig. 1). The following waveform parameters of simple IPSPs were determined: peak amplitude, $10-90 \%$ rise time, rate-of-rise, $10-90 \%$ decay time, half-width, and half-decay-width (Fig. 1). Data representing each waveform parameter were expressed as the mean \pm SD for each motoneuron in the control and experimental (drug) populations. The group mean \pm SEM of the individual means was then obtained for the control and experimental populations of motoneurons.

Segregation of IPSPs for decay phase analyses following the microiontophoretic ejection of GABA antagonists. As presented in Results, the GABA antagonists exerted an unexpected effect that was limited to the repolarization phase of the IPSPs. Therefore, separate IPSP partitioning procedures and analyses were carried out, as described below, to examine this aspect of the data.

The time course of the repolarization of synaptic potentials depends on a number of factors, such as the duration of the underlying synaptic current as well as the cable properties of the cell. These factors also influence the synaptic potentials' rising phase (Rall, 1967; Rall et al., 1967; Jack et al., 1971). In order to determine the extent to which the GABA antagonists affectcd only the rcpolarization phasc of spontancous IPSPs, it was necessary that the rising phase of the IPSPs, under drugfree conditions, be equivalent to the rising phase of the IPSPs recorded under postdrug conditions (see Results). Thus, for this analysis, all simple potentials recorded during active sleep were selected for an examination of their decay phase in both control and postdrug groups on the basis of their having similar $10-90 \%$ rise times.

In the control drug-free population, the group mean $10-90 \%$ rise time of the AS-IPSPs was $0.82 \pm 0.14 \mathrm{msec}$ (see Table 1, Morales et al., 1987). A subpopulation of these simple AS-IPSPs was selected for analysis of their decay phase only if their 10-90\% rise times exceeded 0.68 msec but were less than $0.96 \mathrm{msec}$. This range of rise times corresponds to $1 \mathrm{SD}$ above and below the group mean rise time for the AS-IPSPs. The small-amplitude IPSPs were also subjected to a comparable rise time partitioning procedure $(10-90 \%$ rise-time range, $0.58-0.63 \mathrm{msec}$; see Morales et al., 1987). The $10-90 \%$ decay-time was then defined as the duration of a potential beginning at a point corresponding to $90 \%$ of its amplitude and ending when it reached $10 \%$ of its amplitude on its decay phase (Fig. $1 E$ ). Tables 1 and 2 summarize the waveform parameters of simple AS-IPSPs and small-amplitude IPSPs with common rise times that were recorded under drug-free conditions (Morales et al., 1987). The decay phase of these control IPSPs was then compared with the decay phase of IPSPs with comparable rise times which were recorded from cells exposed to the GABA antagonists.

Statistical procedures. The distributions of IPSP waveform parameters that were skewed and whose variances were different during behavioral states (i.e., quiet sleep vs. active sleep) were compared utilizing a nonparametric statistical test (Mann-Whitney $U$ test). Differences between control and cxpcrimental groups were considered to be statistically significant at $p<0.05$. Differences in the distribution of IPSP frequencies across the control and postdrug population of motoneurons were determined using a $\chi^{2}$ test at $p<0.05$. The Pearson method was utilized for the correlation analyses between different waveform parameters.

\section{Results}

Lumbar motoneurons were impaled during either quiet sleep or the transition into active sleep; all cells were monitored throughout subsequent episodes of active sleep. The effects of microiontophoretically applied inhibitory amino acid antagonists were examined on a total of 35 motoneurons. The average action potential amplitude of these cells was $68.5 \pm 7.1 \mathrm{mV}$ ( $\pm \mathrm{SD}$, range, $55-85 \mathrm{mV}$ ). Each amino acid antagonist was ejected juxtacellularly during quiet sleep or during the initial period of active sleep. The IPSP data that were recorded during active sleep under drug-free conditions, as presented in Morales et al. (1987), served as a control for the IPSP data obtained following the juxtacellular microiontophoresis of strychnine, picrotoxin, and bicuculline methiodide. 


\section{A. Active Sleep, Control}

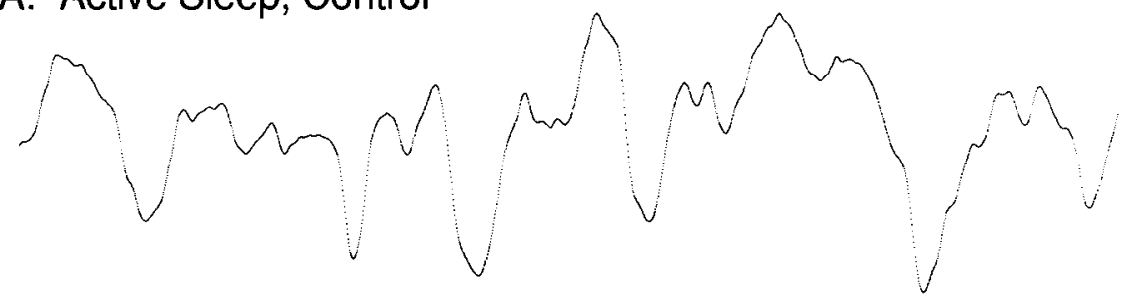

B. Active Sleep, Strychnine

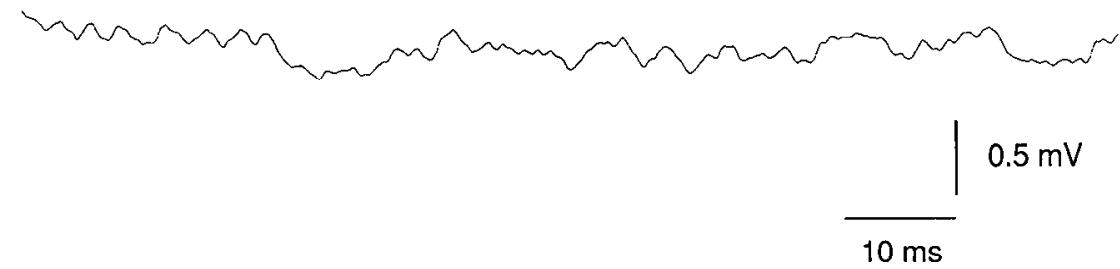

Figure 2. Effect of microiontophoretically ejected strychnine on the membrane potential activity of a sciatic motoneuron recorded during the atonia of active sleep. Each trace is a high-gain record of membrane activity before $(A)$ and after $(B)$ strychnine ejection. Note that the control membrane potential activity during the atonia of active sleep was characterized predominantly by large-amplitude spontaneously occurring IPSPs $(A)$, which were completely abolished $(B)$ following the ejection of strychnine (15 mM, $225 \mathrm{nA}, 1.5 \mathrm{~min}$ ). The tip of the recording micropipette extended $60 \mu \mathrm{m}$ beyond the ejection micropipette (see Materials and Methods), thus allowing strychnine to be ejected adjacent to the somatic portion of the motoneuron. Antidromic spike amplitude, $66 \mathrm{mV}$.

\section{Strychnine}

\section{IPSP frequency}

Strychnine was ejected, juxtacellularly, onto 12 cells during quiet sleep and onto 7 cells during the initial period of active sleep. It was released using an average ejection current of $119.7 \pm$ $65.5 \mathrm{nA}$ (range, $36-250 \mathrm{nA}$ ) over an average time period of 1.5 $\pm 0.6 \mathrm{~min}$ (range, $0.5-3.0 \mathrm{~min}$ ).

As previously reported, the membrane potential of lumbar motoneurons during the atonia of active sleep was dominated by the presence of large-amplitude AS-IPSPs and small-ampli-

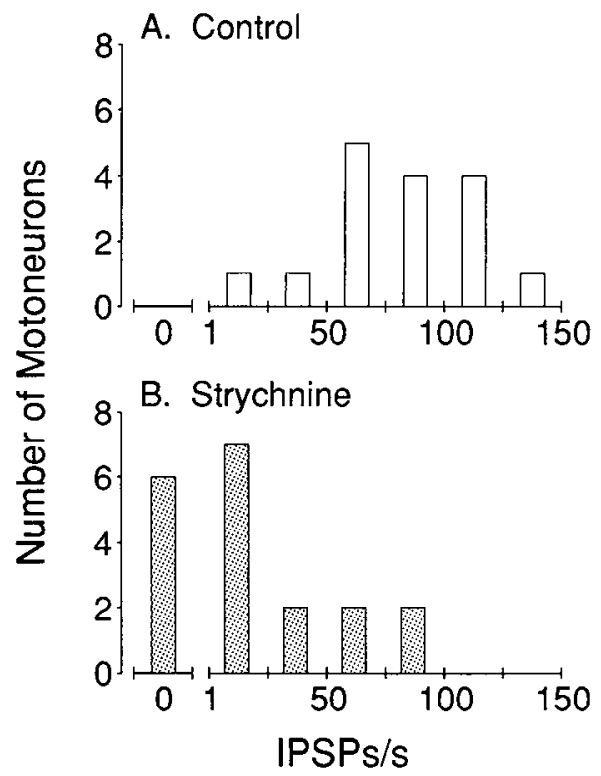

Figure 3. IPSP frequency distribution among motoneurons recorded during active sleep under control, drug-free conditions $(A)$ and following the juxtacellular microiontophoretic application of strychnine $(B)$. As shown in $A, 88 \%$ of the motoneurons exhibited IPSP frequencies in excess of 50 potentials/sec. In contrast, in $B, 79 \%$ of the motoneurons exposed to the juxtacellular application of strychnine were subjected to a substantially weaker inhibitory bombardment, which was characterized by IPSP frequencies below 50 potentials/sec. Note that in $32 \%$ of the motoneurons tested with strychnine, no spontaneous IPSP activity was detected. tude IPSPs (Morales and Chase, 1982; Morales et al., 1987). In 6 motoneurons, strychnine was effective in blocking, completely, all IPSPs. Figure $2 A$ is an example of a high-gain intracellular recording of membrane activity from a lumbar motoneuron during the atonia of active sleep. This cell was impaled during the preceding episode of quiet sleep; its membrane activity was monitored throughout the transition and then during the entire episode of active sleep. Figure $2 B$ is a sample record of highgain membrane activity in the same cell following the juxtacellular ejection of strychnine; note that IPSP activity was completely suppressed and remained so throughout the period of active sleep.

In the remaining 13 cells, following strychnine application, there was some residual IPSP activity, all of which was of small amplitude (see below); the mean IPSP frequency was only $39.9 \%$ of the control, drug-free value (control, 80.3 \pm 35.2 IPSPs/sec;

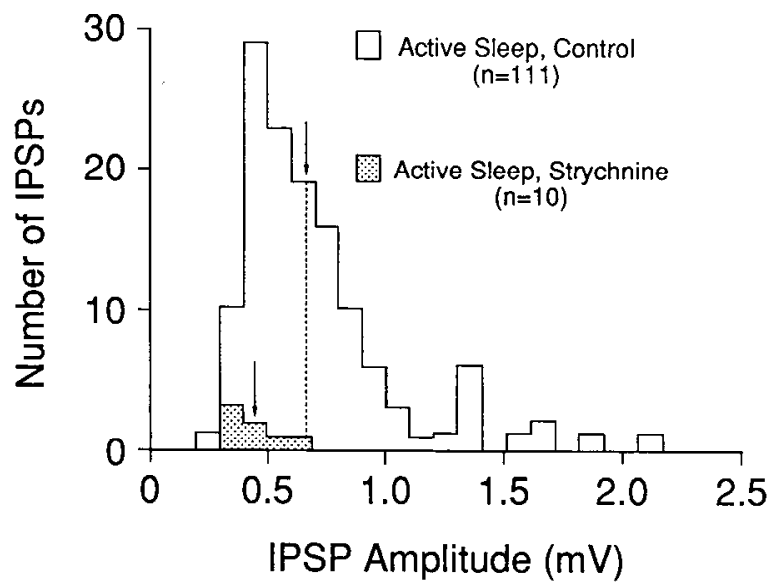

Figure 4. Distribution of the amplitudes of spontaneous IPSPs recorded during active sleep from the same lumbar motoneuron before (open histogram) and following the microiontophoretic ejection of strychnine (dotted histogram). Arrows indicate the median value of each IPSP population. Note that before strychnine, $50 \%$ of the potentials were larger in amplitude than the largest potential which was detected following the microiontophoretic ejection of strychnine $(10 \mathrm{~mm}, 250$ $\mathrm{nA}, 2.75 \mathrm{~min}$ ) 
Figure 5. Scattergrams depicting the relationship between the peak amplitude and $10-90 \%$ rise time of spontaneous IPSPs recorded during active sleep before $(A)$ and immediately following $(B)$ the microiontophoretic ejection of strychnine. IPSPs were still present following strychnine ejection (10 $\mathrm{mM}, 100 \mathrm{nA}, 3.0 \mathrm{~min}$ ); however, they consisted entirely of small-amplitude potentials. The 2 ellipses in $C$ represent the $90 \%$ confidence regions (Sokal and Rohlf, 1981) of the data points corresponding to the potentials recorded during active sleep before and after the ejection of strychnine (as illustrated in $A$ and $B$ ).
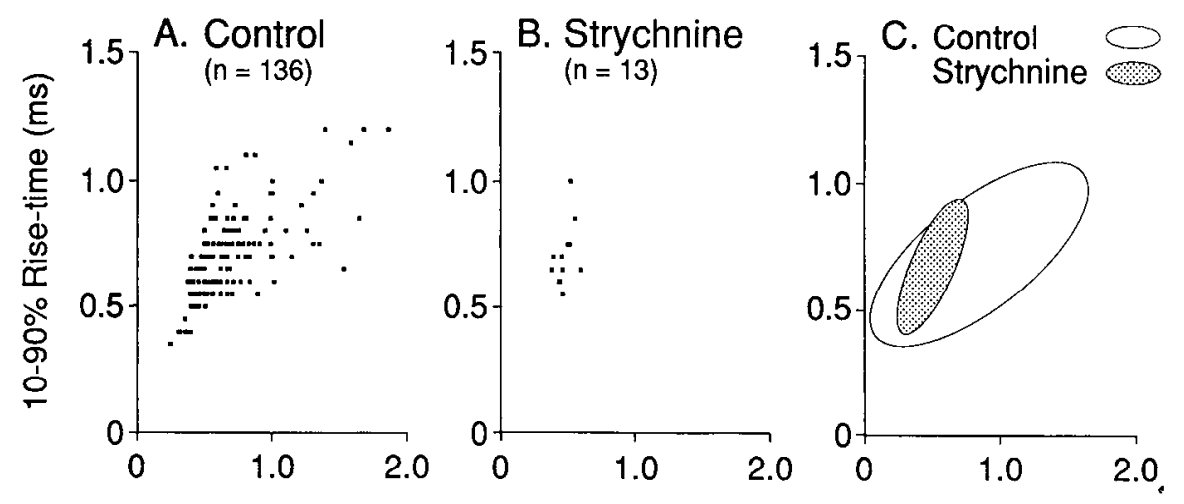

IPSP Amplitude (mV) strychnine, $31.9+28.7$ IPSPs/sec). This difference was statistically significant $(p<0.05)$.

Figure 3 consists of bar histograms depicting the frequency of the spontaneous IPSPs recorded from all motoneurons under control conditions $(A)$ and following the microiontophoretic ejection of strychnine $(B)$. Note that these distributions are markedly different. In the control group, all motoneurons displayed IPSP activity; the IPSP frequency of the majority of motoneurons was greater than 50 potentials/sec. In contrast, the majority of motoneurons tested with microiontophoretic strychnine $(78.9 \%)$ displayed IPSP activity that occurred at frequencies less than 50 potentials/sec; moreover, $32 \%$ of the cells exhibited no IPSP activity whatsoever.

\section{Waveform characteristics of the spontaneous IPSPS which remained following microiontophoretic ejection of strychnine}

Amplitude and rising phase. The mean IPSP amplitude for the entire sample of motoneurons recorded during the control, drugfree periods of active sleep was $0.86 \pm 0.03 \mathrm{mV}$. In contrast, the group mean amplitude, during active sleep, of the IPSPS which remained following strychnine microiontophoresis was $0.52 \pm 0.03 \mathrm{mV}$, or $60.5 \%$ of the control value $(p<0.05)$. Figure 4 is an example of the distribution of IPSP amplitudes in the same motoneuron before and immediately following the juxtacellular ejection of strychnine. The median amplitude of the simple IPSPs in this record was $0.67 \mathrm{mV}$ (indicated by the dotted line and arrow in Fig. 4). Following the ejection of strychnine, only a few IPSPs were present, and these were of small amplitude (median amplitude, $0.44 \mathrm{mV}$ ). For the 13 cells in which IPSPs remained following strychnine, the group mean rise time $(0.61 \pm 0.01 \mathrm{msec})$ was not statistically different from the corresponding control value $(0.68 \pm 0.01 \mathrm{msec} ; p>0.05)$. The rate-of-rise of the spontaneous IPSPs which remained following strychnine was reduced by $33.9 \%$ compared with the corresponding control value (control, $1.27 \pm 0.03 \mathrm{mV} / \mathrm{msec}$; strychnine, $0.84 \pm 0.03 \mathrm{mV} / \mathrm{msec} ; p<0.05$ ).

Figure 5 presents scattergrams $(A, B)$ of the relationship between amplitude and rise time of all simple IPSPs recorded during active sleep from a motoneuron before and after the ejection of strychnine. A relatively large number of IPSPs ( $n=$ 136) were present prior to strychnine administration, and, as described previously (Morales et al., 1987), a direct correlation existed between IPSP amplitude and $10-90 \%$ rise time $(r=0.72$, $p<0.05$ ). However, following strychnine administration, very few IPSPs remained ( $n=13)$; no correlation existed between their amplitude and rise time $(r=0.47, p>0.05)$. The ellipses in Figure $5 \mathrm{C}$ depict the confidence regions (Sokal and Rohlf, 1981) within which are located $90 \%$ of the data points shown in the scattergrams in Figure $5, A, B$. The ellipse representing the IPSPs recorded during active sleep (clear ellipse) was greater in area and displaced to the right compared with that constructed for the IPSPs recorded following the juxtacellular ejection of strychnine (dotted ellipse). These data suggest that the population of large-amplitude IPSPs that are present during the atonia of active sleep are absent following the microiontophoretic ejection of strychnine.

Decay phase. The group mean half-width and half-decay-width of all simple IPSPs that remained following strychnine administration were shorter by 33.8 and $46.2 \%$, respectively, compared with control drug-free values (half-width: control, $2.07 \pm$ $0.06 \mathrm{msec}$ and strychnine, $1.37 \pm 0.06 \mathrm{msec}$; half-decay-width: control, $1.47 \pm 0.06 \mathrm{msec}$ and strychnine, $0.79 \pm 0.05 \mathrm{msec}$ ). These differences were statistically significant in both cases ( $p$ $<0.05$ ).

To summarize, in cells in which potentials remained following the juxtacellular ejection of strychnine, an analysis of the waveform parameters of individual potentials clearly indicted that they were small-amplitude, short-duration IPSPs.

\section{Picrotoxin and bicuculline}

\section{IPSP frequency}

Experiments were also performed to determine whether the GABA antagonists, picrotoxin and bicuculline methiodide, could modify the frequency or the waveform parameters of motoneuron IPSPs during active sleep. The actions of these substances on 16 sciatic motoneurons were examined (12 motoneurons with picrotoxin; 4 with bicucullinc). For all cclls the mean ejection current applied to the picrotoxin-containing drug barrel was $134.2 \pm 75.8 \mathrm{nA}$ (range, $53-320 \mathrm{nA}$ ) over an average time period of $1.3 \pm 0.5 \mathrm{~min}$ (range, $0.5-2.0 \mathrm{~min}$ ). The mean ejection current and time for bicuculline methiodide were $75.5 \pm 37.6$ $\mathrm{nA}$ (range, 35-125 $\mathrm{nA}$ ) and $2.0 \pm 0.5 \mathrm{~min}$ (range, 2-4 min), respectively.

Neither picrotoxin nor bicuculline blocked IPSP activity during active sleep. The mean IPSP frequency following the microiontophoretic ejection of picrotoxin was $89.9 \pm 34.6$ IPSPs/ sec and $63.9 \pm 35.8 \mathrm{IPSP} / \mathrm{sec}$ following bicuculline ejection; these values were not statistically different from the control values ( $p>0.05$, each case). Bar histograms (Fig. 6, $A, B$ ) depicting the frequency of spontaneous IPSP activity recorded across all motoneurons under control conditions and from the entire sample of motoneurons tested following the microion- 
tophoretic ejection of picrotoxin and bicuculline were remarkably similar to those obtained under control drug-free conditions ( $p>0.05$, each case). This is in marked contrast to the effects observed following the microiontophoretic ejection of strychnine.

\section{Peak amplitude and rising phase}

The group means for peak amplitude, $10-90 \%$ rise time and rate-of-rise for all simple IPSPs present during active sleep were analyzed separately for all those motoneurons exposed to the microiontophoretic application of picrotoxin and bicuculline. These parameters did not differ significantly compared with corresponding control, drug-free values ( $p>0.05$, each case). Moreover, neither picrotoxin nor bicuculline had an effect on the amplitude of those simple IPSPs which were selected on the basis of their having similar rise times $(p>0.05$, Tables 1 and 2).

Amplitude distributions as well as scattergrams depicting IPSP amplitude versus $10-90 \%$ rise time were indistinguishable from those of the control, drug-free group. Thus, unlike strychnine, the frequency, amplitude, and rising phase of spontaneous IPSPs following picrotoxin and bicuculline ejection during active sleep did not differ significantly during experimental and control conditions.

IPSP decay phase. Picrotoxin and bicuculline exerted an unexpected action on the repolarization phase of the IPSPs. Compared with control IPSPs, the group means for the 10-90\% decay time, half-width, and half-decay-width of the IPSPs were significantly reduced during active sleep by picrotoxin and bicuculline. Table 1 summarizes the data for AS-IPSPs with common rise times. Table 2 summarizes the data for the smallamplitude IPSPs, which were also selected on the basis of common rise limes.

These data indicate that picrotoxin and bicuculline did not differentially modify the decay phase of any particular group of IPSP, but acted on all spontaneously occurring IPSPs of active sleep. An example of the differences in decay phase is presented in Figure 7, wherein IPSP activity was monitored in the same cell during active sleep before and after picrotoxin microiontophoresis. Simple AS-IPSPs were selected, aligned by their peak amplitude, automatically averaged, and then plotted using a microcomputer. There were comparable numbers of IPSPs before and after drug administration. Following drug release, the

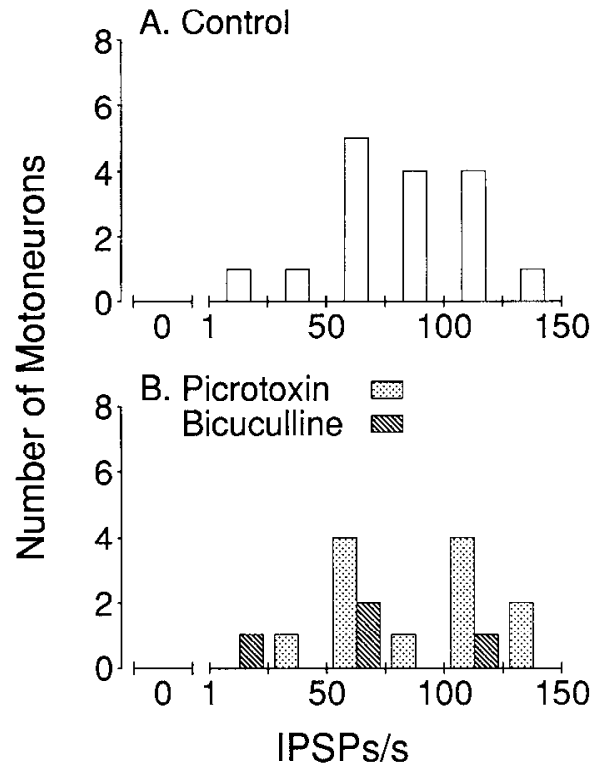

Figure 6. IPSP frequency distribution among motoneurons recorded during the atonia of active sleep under control, drug-free conditions $(A)$ and following the juxtacellular microiontophoretic application of picrotoxin and bicuculline methiodide $(B)$. The data in the control group are the same as described in Figure $3 A$. The overall distribution of IPSP frequencies following the administration of these GABA antagonists was similar to that observed under control, drug-free conditions $(p>$ $0.05)$.

average peak amplitude and rising phase were not statistically different $(p>0.05)$. However, the $10-90 \%$ decay time and halfdecay-width were markedly shorter. These values were $2.32 \pm$ 1.05 and $1.66 \pm 0.71 \mathrm{msec}$ before picrotoxin; following its release, they were $1.62 \pm 0.78$ and $1.28 \pm 0.51 \mathrm{msec}$, respectively $(p<0.05)$. These data correspond to a 30.2 and $22.9 \%$ reduction, respectively, in the values of these waveform parameters. In the 4 motoneurons tested with bicuculline, the decay phase of all IPSPs following bicuculline was also significantly shorter compared with control, drug-free IPSPs (Tables 1 and 2).

To summarize, these data demonstrate that the GABA antagonists picrotoxin and bicuculline did not modify IPSP frequency of occurrence, amplitude, or rising phase, although they

Table 1. Effect of microiontophoretically administered GABA antagonists on the waveform parameters of AS-IPSPs with common rise times

\begin{tabular}{llll}
$\begin{array}{l}\text { AS-IPSP waveform } \\
\text { parameters }\end{array}$ & $\begin{array}{l}\text { Control } \\
(n=10)\end{array}$ & $\begin{array}{l}\text { Picrotoxin } \\
(n=12)\end{array}$ & $\begin{array}{l}\text { Bicuculline } \\
(n=4)\end{array}$ \\
\hline Peak Amplitude (mV) & $1.03 \pm 0.05$ & $0.98 \pm 0.09$ & $0.85 \pm 0.09$ \\
$10-90 \%$ rise time (msec) & $0.79 \pm 0.01$ & $0.79 \pm 0.01$ & $0.79 \pm 0.01$ \\
Rate-of-rise (mV/msec) & $1.23 \pm 0.15$ & $1.32 \pm 0.06$ & $1.10 \pm 0.11$ \\
$10-90 \%$ decay time (msec) & $2.15 \pm 0.12$ & $1.49 \pm 0.09 \dagger$ & $1.45 \pm 0.09 \dagger$ \\
Half-width (msec) & $2.23 \pm 0.06$ & $1.75 \pm 0.05^{*}$ & $1.79 \pm 0.12 \ddagger$ \\
Half-decay-width (msec) & $1.59 \pm 0.05$ & $1.08 \pm 0.02^{*}$ & $1.12 \pm 0.11 \ddagger$ \\
\hline
\end{tabular}

The $n$ value in parentheses indicates the number of cells analyzed in each population of motoneurons (control vs. picrotoxin or bicuculline). Each waveform value represents the group mean \pm SEM for all cells in each population. Spontaneous AS-IPSPs recorded from individual motoneurons in each population were selected such that their $10-90 \%$ rise times exceeded $0.68 \mathrm{msec}$ but were not more than $0.95 \mathrm{msec}$ (see Material and Methods for details). Neither picrotoxin nor bicuculline altered the amplitude or rising phase of these IPSPS $(p>0.05)$; however, each of these compounds markedly reduced their decay phase. The symbols indicate a significant difference from corresponding control values $(* p<0.0005, \dagger p<0.01, \ddagger p<0.05$, Mann-Whitney $U$ test). 


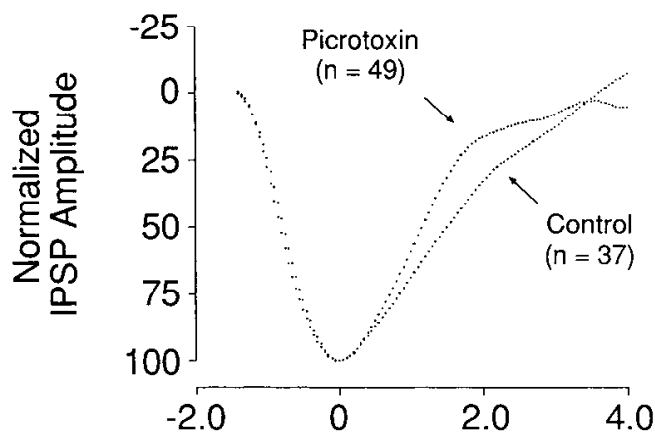

Figure 7. Effect of microiontophoretically ejected picrotoxin on the decay phase of AS-IPSPs. Each trace represents the computerized average of all AS-IPSPs. Picrotoxin, which was ejected during active sleep $(150 \mathrm{nA}, 2.0 \mathrm{~min})$, did not alter the amplitude, $10-90 \%$ rise time, or rate-of-rise of the AS-IPSPs $(p>0.05)$. In order to compare effectively the decay phase of these IPSPs, their amplitudes were normalized. The rising phases of the averaged AS-IPSPs before and after picrotoxin were nearly superimposable. Note, however, that following picrotoxin, the decay phase of the AS-IPSPs was significantly depressed $(p<0.05)$. The averaged $10-90 \%$ decay time, half-width, and half-decay-width were reduced by $30.2,16.7$, and $22.9 \%$, respectively. Similar results were obtained with bicuculline (see text for details). Antidromic spike amplitude, $72 \mathrm{mV}$.

did shorten the repolarization phase of both AS-IPSPs and the small-amplitude IPSPs of active sleep.

\section{Discussion}

The present study was concerned with determining whether glycine and/or GABA are involved in mediating the IPSPs that bombard lumbar motoneurons during the atonia of the nonREM periods of active sleep. The frequency of occurrence and waveform parameters of these IPSPs were examined following the juxtacellular microiontophoretic administration of the glycine antagonist, strychnine, and the GABA antagonists picrotoxin and bicuculline; these data were compared with those that were obtained previously under control drug-free conditions. The actions of these neurotransmitter antagonists on various inhibitory synapses will be discussed with respect to their effects on the IPSPS of active sleep.

\section{Strychnine}

It is well established that strychnine markedly reduces or abolishes Ia and recurrent inhibition as well as the postsynaptic inhibition induced by stimulation of the brain-stem reticular formation (Curtis, 1962, 1969; Kawai and Sasaki, 1964; Llinás, 1964; Curtis et al., 1968a, b; Larson, 1969; Cullheim and Kellerth, 1981). In addition, we have recently demonstrated that strychnine suppresses the IPSPs that are induced in lumbar motoneurons during the atonia of active sleep following stimulation of the medullary nucleus reticularis gigantocellularis (Soja et al., 1987).

Microiontophoretic experiments have convincingly shown that strychnine antagonizes the postsynaptic inhibitory actions of $\alpha$ and $\beta$-amino acids such as glycine and $\beta$-alanine, but not those of $\gamma$-amino acids such as GABA (Curtis et al., 1968a, b). Autoradiographic studies have shown dense labeling of ${ }^{3} \mathrm{H}$ glycine in the ventral horn neuropil (Price et al., 1976). Indeed, van den Pol and Gorcs (1988) recently reported that lumbar motoneurons and their proximal dendrites receive numerous glycine-immunoreactive boutons. These and other studies provide evidence that glycine (or a structurally related compound) is probably a neurotransmitter that is released from the terminals of segmental inhibitory interneurons that impinge on $\alpha$-motoneurons (Curtis et al., 1968a, b; Werman et al., 1968; see also reviews by Curtis, 1969; Davidoff and Hackman, 1983; Young and MacDonald, 1983). Our finding that AS-IPSPs were sup-p pressed or abolished by microiontophoretic strychnine strongly suggests, on the basis of this compound's documented actions, that these inhibitory potentials are also mediated by glycine or glycine-like substances.

We suggest that the AS-IPSPs are generated by local spinal cord inhibitory interneurons because there is no evidence to support the existence of a long monosynaptic inhibitory projection to motoneurons of the lumbar spinal cord from brainstem sites (Jankowska et al., 1968; Baldissera et al., 1981). Spinal cord Ia inhibitory interneurons or Renshaw cells may be considered as candidate sources; their inhibitory actions on spinal motoneurons are known to be reduced or abolished by strychnine (Curtis, 1962, 1969; Larson, 1969; Curtis et al., 1976; Cullheim and Kellerth, 1981). In addition, the motor inhibitory interneurons recently described by Hongo et al. (1983) may be involved in generating these IPSPs. At the present time only Renshaw cells can be excluded from participating in the postsynaptic inhibition of lumbar motoneurons during the atonia of active sleep (Morales et al., 1988).

The population of IPSPs that remained following the microiontophoresis of strychnine resembled, in terms of their amplitude distribution and the relationship between their ampli-

Table 2. Effect of microiontophoretically administered GABA antagonists on the waveform parameters of small-amplitude IPSPs with common rise times which are present during active sleep

\begin{tabular}{llll}
$\begin{array}{l}\text { IPSP waveform } \\
\text { parameters }\end{array}$ & $\begin{array}{l}\text { Control } \\
(n=10)\end{array}$ & $\begin{array}{l}\text { Picrotoxin } \\
(n=12)\end{array}$ & $\begin{array}{l}\text { Bicuculline } \\
(n=4)\end{array}$ \\
\hline Peak amplitude $(\mathrm{mV})$ & $0.71 \pm 0.04$ & $0.71 \pm 0.03$ & $0.61 \pm 0.05$ \\
$10-90 \%$ rise time $(\mathrm{msec})$ & $0.60 \pm 0.01$ & $0.60 \pm 0.01$ & $0.60 \pm 0.01$ \\
Rate-of-rise $(\mathrm{mV} / \mathrm{msec})$ & $1.14 \pm 0.08$ & $1.19 \pm 0.05$ & $0.99 \pm 0.90$ \\
$10-90 \%$ decay time $(\mathrm{msec})$ & $1.71 \pm 0.15$ & $1.09 \pm 0.17^{* *}$ & $1.13 \pm 0.11 \dagger$ \\
Half-width (msec) & $1.71 \pm 0.05$ & $1.29 \pm 0.09^{* *}$ & $1.35 \pm 0.05^{* *}$ \\
Half-decay-width (msec) & $1.18 \pm 0.05$ & $0.81 \pm 0.09^{* *}$ & $0.84 \pm 0.04^{* *}$
\end{tabular}


tude and rise time, the small-amplitude IPSPs which inhibit motoneurons during active sleep (as well as during quiet sleep and wakefulness; see Morales et al., 1987). We cannot be unequivocally certain whether the IPSPs that remained in some cells after strychnine application are the small-amplitude IPSPs of active sleep or if they are AS-IPSPs whose amplitudes have been only partially suppressed by strychnine. However, the results of the present study indicate that both groups of potentials may be mediated by glycine because, in several of the motoneurons examined, all inhibitory synaptic potentials were abolished by strychnine administration.

One explanation for the finding that even repeated microiontophoretic ejections of strychnine were not totally effective in blocking small-amplitude IPSP activity in some cells pertains to the general difficulties associated with microiontophoretic experiments (see review by Stone, 1985). For example, if a drug is ejected onto or near the soma of the cell that is being recorded, synapses located on the dendritic tree may be less affected because of a diminished concentration of the ejected drug. Thus, strychnine-sensitive IPSPs generated at distal dendritic sites may be only partially blocked, or even unaffected, by somatic drug applications. Indeed, the small-amplitude IPSPs of active sleep appear to originate from synapses located more distally than those of the AS-IPSPs (Morales and Chase, 1982; Engelhardt et al., 1985). Thus, by virtue of their synaptic location alone, the small-amplitude IPSPs may be less susceptible to juxtasomatically applied strychnine.

\section{Picrotoxin and bicuculline}

The consensus from electrophysiological experiments performed in vivo and in vitro is that picrotoxin and bicuculline are effective antagonists for the postsynaptic inhibitory actions of $\gamma$-amino acids such as GABA (Curtis et al., 1968a, 1971; Krnjević et al., 1976; Johnston, 1978; Nistri, 1983; Alger, 1985). There is also evidence that these drugs can suppress certain postsynaptic inhibitory processes of lumbar motoneurons that are resistant to strychnine (Kellerth and Szumski, 1966a, b; Cullheim and Kellerth, 1981). Recently, Rudomin et al. (1987) have identified a group of lumbar spinal cord interneurons whose activity is associated with both inhibitory ventral root potentials and negative dorsal root potentials. They suggested that these cells are interposed in pathways mediating the presynaptic inhibition of group I afferent fibers and the postsynaptic inhibition of lumbar motoneurons. Considerable evidence also indicates that presynaptic inhibition is mediated by GABA (see reviews by Levy, 1977; Davidoff and Hackman, 1985); thus, these cells most likely also release GABA at their terminals on motoneurons. The presence of glutamic acid decarboxylase (GAD)-containing synaptic terminals located presynaptic to the soma and proximal dendrites of individual lumbar motoncurons provides immunocytochemical evidence for this type of postsynaptic inhibition (McLaughlin et al., 1975; Robinson and Goldberger, 1986).

The possible involvement of GABA in mediating the IPSPs of active sleep was addressed in the present study by examining the ability of microiontophoretically released picrotoxin and bicuculline to suppress the frequency and modify the waveform of these synaptic potentials. In the present study, picrotoxin and bicuculline failed to decrease the frequency of IPSPs that bombard lumbar motoneurons during active sleep. Moreover, these compounds did not alter the group mean amplitude, 10-90\% rise time, or rate-of-rise of these IPSPs. Therefore, the inhibition by these potentials, of lumbar motoneurons during active sleep, does not appear to be mediated by GABA. A logical inference from these findings is that the spinal cord GABAergic interneurons that convey both presynaptic and postsynaptic afferent inhibitory input to lumbar motoneurons (Rudomin et al., 1987) are not likely to be directly responsible for promoting the IPSPs of active sleep.

Bicuculline and picrotoxin, however, did modify the 10-90\% decay time, half-width, and half-decay-width of both groups of IPSPs during active sleep. It is possible that picrotoxin or bicuculline exerted a direct effect on the membrane of the recorded motoneurons, as has been reported for other neurons. For example, Blaxter et al. (1986) found that picrotoxin can increase the input conductance of hippocampal pyramidal celis. Similarly, microiontophoretically applied bicuculline has been shown to increase the input conductance of lumbar motoneurons in anesthetized cats (Krnjević et al., 1976). If a drug increases membrane conductance, a decrease in the membrane time constant is likely, which would lead, in turn, to a shorter decay phase for synaptic potentials (Rall, 1960; Carlen and Durand, 1981). Thus, a decrease in the motoneuron's membrane time constant produced by picrotoxin or bicuculline could explain the shortened decay phase of the IPSPs during active sleep.

An alternative explanation for the shorter decay phase of these IPSPs (and small-amplitude IPSPs) following the juxtacellular ejection of GABA antagonists is that these drugs may act on one or more components of the synaptic currents underlying the AS-IPSPs. The AS-IPSPs are reversed to depolarizing potentials by the intracellular microiontophoresis of chloride ions (Morales and Chase, 1982). Picrotoxin and bicuculline are known to act on GABA receptor-coupled chloride channels; the former compound apparently binds directly to and modulates GABA receptor-coupled chloride channels, while the latter compound appears to compete directly with GABA for high-affinity GABAergic binding sites associated with the GABA receptor/chloride ionophore complex (Olsen et al., 1978; Akaike et al., 1985). In cultured mouse spinal cord cells, picrotoxin has been reported to block long-lasting inward (chloride-mediated) currents that occur spontaneously as well as those which are activated by bath-applied GABA (Barker, 1985). Bicuculline has also been reported to block spontaneous currents of rat hippocampal pyramidal cells (Collingridge et al., 1984), which suggests that GABA, in this system, is tonically released from nearby inhibitory interneurons. However, under our recording conditions, it is not known whether bicuculline is acting at presumed GABA receptors located on the recorded motoneuron somata (Robinson and Goldberger, 1986) or whether this GABA antagonist (and picrotoxin) is interfering with chloride channels coupled to strychnine-sensitive glycine receptors. The action of both GABA antagonists on the decay phase of the spontaneous IPSPs could rcflcct, in part, a unique role for segmentally released GABA in modulating the chloride channel kinetics of the glycinergic IPSPs that bombard lumbar motoneurons during active sleep.

\section{Conclusions}

The electrophysiological data of this study confirm our previous observation that lumbar motoneurons are subjected to a barrage of discrete inhibitory postsynaptic potentials during the nonREM periods of active sleep. The pharmacological data indicate that glycine (or a glycinergic substance) is the inhibitory neurotransmitter that mediates these active sleep-specific IPSPs. 


\section{References}

Akaike, N., K. Hattori, Y. Oomura, and D. O. Carpenter (1985) Bicuculline and picrotoxin block $\gamma$-aminobutyric acid-gated $\mathrm{Cl}^{-}$conductance by different mechanisms. Experientia 41: 70-71.

Alger, B. E. (1985) GABA and glycine: Postsynaptic actions. In Neurotransmitter Actions in the Vertebrate Nervous System, M. A. Rogawski and L. L. Barker, eds., pp. 33-69, Plenum, New York.

Baldissera, F., H. Hultborn, and M. Illert (1981) Integration in spinal neuronal systems. In Handbook of Physiology, Vol. 2, The Nervous System, Part 1, Motor Control, pp. 509-596, American Physiological Society, Bethesda, MD.

Barker, J. L. (1985) GABA and glycine: Ion channel mechanisms. In Neurotransmitter Actions in the Vertebrate Nervous System, M. A. Rogawski and L. L. Barker, eds., pp. 71-100, Plenum, New York.

Blaxter, T. J., P. L. Carlen, M. F. Davies, and P. W. Kutjan (1986) $\gamma$-Aminobutyric acid hyperpolarizes rat hippocampal pyramidal cells through a calcium-dependent potassium conductance. J. Physiol. (Lond.) 373: 181-194.

Carlen, P. L., and D. Durand (1981) Modelling the postsynaptic location and magnitude of tonic conductance changes resulting from neurotransmitters or drugs. Neuroscience $6: 839-846$.

Chase, M. H., and F. R. Morales (1982) Phasic changes in motoneuron membrane potential during REM periods of active sleep. Neurosci. Lett. 34: 177-182.

Chase, M. H., and F. R. Morales (1983) Subthreshold excitatory activity and motoneuron discharge during REM periods of active sleep. Science 221: 1195-1198.

Collingridge, G. L., P. W. Gage, and B. Robertson (1984) Inhibitory post-synaptic currents in rat hippocampal CAl neurones. J. Physiol. (Lond.) 356: 551-564.

Cullheim, S., and J.-O. Kellerth (1981) Two kinds of recurrent inhibition of cat spinal $\alpha$-motoneurones as differentiated pharmacologically. J. Physiol. (Lond.) 312: 209-224.

Curtis, D. R. (1962) The depression of spinal inhibition by electrophoretically administered strychnine. Int. J. Neuropharmacol. 1:239250.

Curtis, D. R. (1969) The pharmacology of spinal postsynaptic inhibition. In Progress in Brain Research, Vol. 31: Mechanisms of Synaptic Transmission, K. Akert and P. G. Waser, eds., pp. 171-189, Elsevier, Amsterdam.

Curtis, D. R., L. Hösli, and G. A. R. Johnston (1968a) A pharmacological study of the depression of spinal neurones by glycine and related amino acids. Exp. Brain Res. 6: 1-18.

Curtis, D. R., L. Hösli, G. A. R. Johnston, and I. H. Johnston (1968b) The hyperpolarization of spinal motoneurones by glycine and related amino acids. Exp. Brain Res. 5: 235-258.

Curtis, D. R., A. W. Duggan, D. Felix, and G. A. R. Johnston (1971) Bicucullinc, an antagonist of GABA and synaptic inhibition in the spinal cord of the cat. Brain Res. 32: 69-96.

Curtis, D. R., C. J. A. Game, D. Lodge, and R. M. McCulloch (1976) A pharmacological study of Renshaw cell inhibition. J. Physiol. (Lond.) 258: $227-242$

Davidoff, R. A., and J. C. Hackman (1983) Spinal inhibition. In Handbook of the Spinal Cord, Vols. 2 and 3: Anatomy and Physiology, R. A. Davidoff, ed., pp. 385-459, Marcel Dekker, New York.

Davidoff, R. A., and J. C. Hackman (1985) GABA: Presynaptic actions. In Neurotransmitter Actions in the Vertebrate Nervous System, M. A. Rogawski and L. L. Barker, eds., pp. 3-32, Plenum, New York.

Engelhardt, J. K., F. R. Morales, P. J. Soja, and M. H. Chase (1985) Location on alpha-motoneurons of synapses responsible for spontaneous IPSPs occurring during active sleep or carbachol-induced atonia. Biophys. J. 47: 51a (abstr.).

Hongo, T., E. Jankowska, T. Ohno, S. Sasaki, M. Yamashita, and K. Yoshida (1983) The same interneurones mediate inhibition of dorsal spinocerebellar tract cells and lumbar motoneurones in the cat. J. Physiol. (Lond.) 342: 161-180.

Jack, J. J. B., S. Miller, R. Porter, and S. J. Redman (1971) The time course of minimal excitatory post-synaptic potentials evoked in spinal motoneurones by group Ia afferent fibres. J. Physiol. (Lond.) 215: $353-380$.

Jankowska, E., S. Lund, A. Lundberg, and O. Pompeiano (1968) Inhibitory effects evoked through ventral reticulospinal pathways. Arch. Ital. Biol. 106: 124-140.

Johnston, G. A. R. (1978) Neuropharmacology of amino acid inhibitory transmitters. Annu. Rev. Pharmacol. Toxicol. 18: 269-289.
Kawai, I. and L. Sasaki (1964) Effects of strychnine upon supraspinal inhibition. Jpn. J. Physiol. 14: 309-317.

Kellerth, J.-O., and A. J. Szumski (1966a) Two types of stretch-activated post-synaptic inhibitions in spinal motoneurones as differentiated by strychnine. Acta Physiol. Scand. 66: 133-145.

Kellerth, J.-O., and A. J. Szumski (1966b) Effects of picrotoxin on stretch-activated post-synaptic inhibitions in spinal motoneurones. Acta Physiol. Scand. 66: 146-156.

Krnjević, K., E. Puil, and R. Werman (1976) Bicuculline, benzyl penicillin, and inhibitory amino acids in the spinal cord of the cat. Can. J. Physiol. Pharmacol. 55: 670-680.

Larson, M. D. (1969) An analysis of the action of strychnine on the recurrent IPSP and amino acid induced inhibitions in the cat spinal cord. Brain Res. 15: 185-200.

Levy, R. A. (1977) The role of GABA in primary afferent depolarization. Prog. Neurobiol. 9: 211-267.

Llinás, R. (1964) Mechanisms of supraspinal actions upon spinal cord activities, Pharmacological studies on reticular inhibition of alpha extensor motoneurons. J. Neurophysiol. 27: 1127-1137.

McLaughlin, B. J., R. Barber, K. Saito, E. Roberts, and J. Y. Wu (1975) Immunocytochemical localization of glutamate decarboxylase in the rat spinal cord. J. Comp. Neurol. 164: 305-322.

Morales, F. R., and M. H. Chase (1982) Repetitive synaptic potentials responsible for inhibition of spinal cord motoneurons during active sleep. Exp. Neurol. 78: 471-476.

Morales, F. R., J. Schadt, and M. H. Chase (1981) Intracellular recording from spinal cord motoneurons in the chronic cat. Physiol. Behav. 27: 355-362.

Morales, F. R., A. Baranyi, P. J. Soja, and M. H. Chase (1984) The spontaneous IPSPs involved in motoneuron inhibition during active sleep are blocked by strychnine. Soc. Neurosci. Abstr. 10: 747.

Morales, F. R., P. A. Boxer, J. P. Jervey, and M. H. Chase (1985) A computerized system for the detection and analysis of spontaneously occurring synaptic potentials. J. Neurosci. Methods 13: 19-35.

Morales, F. R., P. A. Boxer, and M. H. Chase (1987) Behavioral statespecific inhibitory postsynaptic potentials impinge on cat lumbar motoneurons during active sleep. Exp. Neurol. 98: 418-435.

Morales, F. R., J. K. Engelhardt, A. E. Pereda, J. Yamuy, and M. H. Chase (1988) Renshaw cells are inactive during motor inhibition elicited by pontine microinjection of carbachol. Neurosci. Lett. 86 : 289-295.

Nistri, A. (1983) Spinal cord pharmacology of GABA and chemically related amino acids. In Handbook of the Spinal Cord. Vol. 1: Pharmacology, R. A. Davidoff, ed., pp. 45-104, Marcel Dekker, New York.

Olsen, R. W., M. K. Ticku, C. VanNess, and D. Greenlee (1978) Effects of drugs on $\gamma$-aminobutyric acid receptors, uptake, relcase and synthesis in vitro. Brain Res. 139: 277-294.

Price, D. L., A. Stocks, J. W. Griffin, A. Young, and K. Peck (1976) Glycine-specific synapses in rat spinal cord. J. Cell Biol. 68: 389-395.

Rall, W. (1960) Membrane potential transients and membrane time constants of motoneurons. Exp. Neurol. 2: 502-532.

Rall, W. (1967) Distinguishing theoretical synaptic potentials computed for different soma-dendritic distributions of synaptic input. J. Neurophysiol. 30: 1138-1168.

Rall, W., R. E. Burke, T. G. Smith, P. G. Nelson, and K. Frank (1967) Dendritic location of synapses and possible mechanisms of other monosynaptic EPSPs in motoneurons. J. Neurophysiol. 30: 11691193

Robinson, G. A., and M. E. Goldberger (1986) The development and recovery of motor function in spinal cats. II. Pharmacological enhancement of recovery. Exp. Brain Res. 62: 387-400.

Rudomin, P., M. Solodkin, and I. Jiménez (1987) Synaptic potentials of primary afferent fibers and motoneurons evoked by single intermediate nucleus interneurons in the cat spinal cord. J. Neurophysiol. 57: 1288-1313.

Soja, P. J., F. R. Morales, and M. H. Chase (1986) Effect of picrotoxin and bicuculline on the waveform characteristics of spontaneous IPSPs involved in lumbar motoneuron inhibition during active sleep. Soc. Neurosci. Abstr. 12: 251 .

Soja, P. J., F. R. Morales, A. Baranyi, and M. H. Chase (1987) Effect of inhibitory amino acid antagonists on IPSPs induced in lumbar motoneurons upon stimulation of the nucleus reticularis gigantocellularis during active sleep. Brain Res. 423: 353-358.

Sokal, R. R., and F. J. Rohlf (1981) Biometry, Freeman, San Francisco. Stone, T. W. (1985) Microiontophoresis and pressure ejection. In 
IBRO Handbook Series: Methods in the Neurosciences, Vol. 8, A. D. Smith, ed., Wiley, New York.

van den Pol, A. N., and T. Gorcs (1988) Glycine and glycine receptor immunoreactivity in brain and spinal cord. J. Neurosci. 8: 472-492.

Werman, R., R. A. Davidoff, and M. H. Aprison (1968) Inhibitory action of glycine on spinal neurons in the cat. J. Neurophysiol. 31: $81-95$.

Young, A. B., and R. L. MacDonald (1983) Glycine as a spinal cord neurotransmitter. In Handbook of the Spinal Cord, Vol. 1: Pharmacology, R. A. Davidoff, ed., pp. 1-44, Marcel Dekker, New York. 